\title{
A virtude e a forma epistolar: uma leitura de Pamela, or virtue rewarded
}

Virtue and epistolary form: a reading of Pamela, or virtue rewarded

Felipe Vale da Silva ${ }^{1}$

Doutorando em Letras (Literatura Alemã) pela Universidade de Sáo Paulo e bolsista do $\mathrm{CNPq}$

felipe.vale.silva@usp.b
RESUMO: 0 artigo discute o uso da forma epistolar e exploração do conceito de virtude em Pamela, or virtue rewarded (1740) de Samuel Richardson A importância de Richardson na literatura europeia é inegável, mas ainda se fala muito pouco a respeito de seu posicionamento nos debates de filosofia moral cruciais para o desenvolvimento da crítica iluminista da sociedade. Entender Richardson em sua singularidade e à luz de estudos mais recentes sobre o século XVIII é, portanto, a forma com que busco contribuir com os estudos do romance do Iluminismo.

PALAVRAS-CHAVE: Romance Epistolar; Iluminismo; Samuel Richardson; Sentimentalismo; Crítica.

ABSTRACT: The article analyzes the use of epistolary form and the approach to the concept of virtue in Samuel Richardson's Pamela, or virtue rewarded (1740). In spite of Richardson's undeniable importance to European literature, still very few is said about his role within the debates on moral philosophy crucial to the development of the social criticism of the Enlightenment. Understanding Richardson's work, thus, in its singularity and in the light of more recent studies on the $18^{\text {th }}$ Century is the way in which I intend to contribute with the studies of the novel of the Enlightenment.

KEYworDS: Epistolary Novel; Enlightenment; Samuel Richardson; Sentimentalism; Critique. 
$\mathrm{H}^{2}$ á algumas décadas observamos a renovação do interesse acadêmico pela literatura do século XVIII. À primeira vista, essa época é capaz de despertar nosso interesse por se tratar de um período de origens; foi nesse momento da história que surgiram textos centrais das várias literaturas nacionais que definem a produção textual até hoje, e nos quais foram formulados problemas que ainda são nossos problemas (STANITZEK, 1999, p. 249).

Mas é um segundo aspecto dos estudos recentes sobre o século XVIII que serviu de motivação para este artigo. Uma influente tradição de pensamento inspirada pela filosofia de Hegel valeu-se do termo Iluminismo como slogan de um movimento intelectual que, embora internacional, funcionou como tendência homogênea, e, embora revolucionária nas sociedades em que se desenvolveu, deixou-se guiar por um uso dogmático da racionalidade, negligenciando outras dimensões importantes de nossa experiência - a fantasia, o sentimento, o mundo das pulsões -, às quais somente a filosofia e movimentos artísticos posteriores souberam dar devida atenção. Assumiuse por muito tempo que, no campo da literatura, o movimento se deixou limitar por uma estética muito restritiva, unicamente interessada em educar e moralizar seus leitores a partir de preceitos racionalistas (ALT, 2007, p. 6).

Essa imagem do iluminismo, difundida da Fenomenologia do Espírito (1807) de Hegel à Dialética do Iluminismo (1944) de Adorno e Horkheimer, vem sido provada como insuficiente por estudos mais recentes. ${ }^{1}$ Iluminismo é antes um conceito de época que engloba uma pluralidade de tendências e manifestações culturais que, por vezes, contradizem umas com as outras e ainda estão sendo compreendidas pelas humanidades. É equivocado assumirmos a existência de uma forma pronta da visão de mundo desse

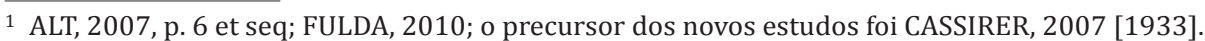

movimento. Ao contrário, na época operou-se uma abertura e pluralização das formas de interpretar o mundo, uma vez que as formas tradicionais de agir, pensar e crer dominantes desde a Idade Média viraram objeto de contestação. Nada foi deixado sem questionar, seja hierarquia social, a razão ou o próprio Deus. "O mundo pareceu então mais aberto do que nunca dantes, e modelável a partir de novos princípios" (FULDA, 2010, p. 6).² Quando pensamos no modelo cultura Iluminismo hoje, portanto, devemos pensar na tendência internacional que alterou os passos da Europa e suas colônias no decorrer do século, em face dessa situação de abertura. Daí deriva a necessidade de repensar textos individuais da época sem recorrer a generalizações comuns.

No ponto de vista dos próprios iluministas, o processo de Esclarecimento começara na Grécia Antiga, voltando a atuar na Europa a partir da Renascença e das reformas do século XVI (ALT, 2007, p. 5 e 316). Figuras como Voltaire e Wieland se viam como parte de uma vanguarda intelectual transecular, empenhada em abrir terreno para um processo global de aperfeiçoamento da espécie humana. Para atingir esse alvo, eles assumiram a tarefa de articular formas de pensar a vida criticamente; não a vida idealizada dos grandes heróis da Antiguidade, mas vida comum do século XVIII. O grande romance europeu da época destacou-se por popularizar meios de retratar a vida comum com seriedade, e aquele que atua nela, o homem corriqueiro, com dignidade.

O romance, como gênero refletor da sociedade que emoldura cada personagem, também teve uma atuação revolucionária à sua própria maneira: ao expor o mundo das relações humanas em uma chave mais realista, ele serviu como um importante articulador de uma cultura de deflagração de crises (moral, social, espiritual) das sociedades estratificadas

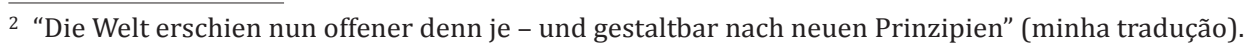


para, posteriormente, exigir a solução dessas crises. ${ }^{3}$ Esse é um fator a ser levado em conta quando pensamos no tom moralizante presente nos textos de autores como Defoe, Fielding e Richardson. Tais autores exigiam a mudança do mundo retratando o heroísmo de indivíduos questionadores do status quo, ao mesmo tempo em que enfatizavam suas mostras de fibra moral em meio a um mundo corrompido. Foi no conceito de virtude que todos eles encontraram um signo adequado para remeter à dimensão anímica que desde a Antiguidade esteve ligada ao controle-de-si, traço essencial a todo indivíduo que se julga racional e livre. Daí a obsessão de alguns autores setecentistas com o valor prático de suas obras, algo que contribuiu para que esta fase de produção artística europeia ganhasse certo ar de rigidez. Isso ocorreu já que tais autores compartilharam a tarefa de criticar o mundo atual e, adicionalmente, compuseram suas obras sob a convicção utilitarista que via o livro como um instrumento educador da humanidade. Para eles, o motivo principal da escrita era claro: o romance deveria falar da virtude com o fim de tornar seus leitores virtuosos.

O nome de Samuel Richardson é comumente evocado como um caso extremo do utilitarismo de seu século. Sua forma de escrever romances convenceu um enorme público leitor de que o consumo de obras de ficção equivale (ou deveria equivaler) a um exercício de crescimento pessoal. Como tratarei em seguida, livros ao estilo de Richardson preencheram as estantes de bibliotecas da época, e receberam imitações de diferentes graus de sucesso em diversas línguas europeias até a geração seguinte. A forma como tratou da questão da virtude em seu que seu livro inaugural, Pamela, or virtue rewarded, por fim, ultrapassou os limites do gênero do romance para inspirar uma rica tradição de drama cujos porta-vozes são figuras centrais da dramaturgia setecentista: Diderot, Mercier e Lessing.

3 Da mesma forma que a filosofia crítica a partir de Bayle funcionou no campo do discurso das ciências humanas; KOSELLECK, 1999, p. 9. Este ponto será melhor desenvolvido em seguida.
O estilo e influência do grande autor, contudo, perdeu a força com o passar dos séculos. Junto a outros escritores modelares, Richardson revolucionou a forma que a cultura da modernidade entende o formato romance - mas precisou ser superado de uma forma ou de outra. Ler Richardson hoje, por conseguinte, parece exigir certa preparação por parte do leitor. Tal opinião é expressa por Arnold Hauser, que entende os romances de Richardson como

[...] fundamentally moral tracts in the form of pathetic love stories. The author takes on the role of a spiritual adviser, discusses the great problems of life, forces the reader to examine himself, clears up his doubts and helps him with fatherly counsel. He has been rightly called a 'Protestant father confessor', and it was not for nothing that his books were recommended from the pulpit. (HAUSER, 1999, p. 60)

De acordo com o historiador, o romance do século XVIII precisou subordinar-se aos ditames das grandes forças atuantes no antigo regime inglês - a religiosidade puritana, o código social da estratificação. Quando tais grandes narrativas perdem influência na cultura geral, todo um conjunto de obras literárias antigas se torna irrelevante e inatual.

Será justamente tal atualidade que pretendo resgatar neste artigo. Buscarei expor uma leitura do autor inglês que questiona o estereótipo de moralista perpetuado por gerações de historiadores da literatura. Argumentarei, sobretudo, como o tema da virtude no romance jamais foi um ponto pacífico para os grandes expoentes do gênero, e muito menos correspondeu ao que o senso comum entendia pelo termo. Temos documentadas diversas polêmicas entre escritores como Fielding e Richardson, que se valiam de seus próprios romances para abordar questões centrais de filosofia. Ao invés de recorrerem a códigos morais disponíveis na época, eles levaram o debate acerca da moral a um novo patamar. o tema da virtude passou a ser explorado a partir de uma narrativa 
com coerência interna, em que personagens dotadas de profundidade psicológica se confrontavam com problemas análogos aos problemas do mundo real. A própria forma do romance impedia um tratamento prescritivo da moral, e por isso mesmo tornou-se atrativa para os leitores da época.

Cabe responder preliminarmente: por que esses escritores decidiram questionar as antigas formas de abordar o tema da virtude? Um dos motivo por trás disso foi de ordem epistemológica. Romancistas da época incorporaram em sua própria escritura, como pouco se viu dantes, o problema da correspondência entre obra literária e realidade que ela mimetiza. Um grande apreciador de romances da época, Adam Smith, chegou a afirmar que o método com que romancistas retratavam questões de moral resultava mais eficaz que o método da própria filosofia - e Smith o fez em seu próprio tratado filosófico, The Theory of Moral Sentiments (1759):

The poets and romance writers, who best paint the refinements and delicacies of love and friendship, ad of all other private and domestic affections [...] are [...] much better instructors than [the philosophers] Zeno, Chrysippus, or Epictetus. (SMITH apud SIEGEL, 2005, p. 150)

A colocação de Smith merece ser explorada por um momento. Talvez seja possível entendê-la melhor voltando ao instante histórico em que escritores como Defoe, Fielding e Richardson compuseram suas obras, inconscientemente ditando as tendências do romance posterior. $\mathrm{O}$ que ligou esses três grandes nomes foi um ímpeto de renovar as formas tradicionais de retratar o mundo. Se antes a literatura imitava a realidade por meio de "quadros lisonjeiros da humanidade" (WATT, 2010, p. 11), representados por personagens heroicas e idealizadas, nesse instante o romance se diferenciou como registro textual apto a fazer uma "análise da vida mais desapaixonada e científica” (idem). Assim, quando se afirma que a virtude foi um dos grandes temas do romance setecentista, portanto, deve-se levar em conta que ela apareceu nas páginas de cada novo livro da época como categoria problemática, aberta à exploração. Diferente de tratados filosóficos, o novo romance era capaz de retratar o sujeito moral como um ser indissociado de sua dimensão social. O indivíduo, assim, era tomado como unidade indivisível, capaz de ser analisada somente em sua radical atualidade. Disso seguia-se que a compreensão da personagem seria sempre incompleta caso não fosse acompanhada pela análise da sociedade que a emoldura - sociedade que, nos melhores casos, se revelava inquietantemente próxima àquela em que os leitores viviam suas vidas. ${ }^{4}$

Nesse sentido, alio-me à perspectiva de alguns historiadores da literatura de que a tradição inglesa do romance se formou como uma espécie de "cultura adversária" em seu século de surgimento (KARL apud VASCONCELOS, 2007, p. 22). Diferente do drama ou da épica, ele diferenciou-se por atuar como um corpo estranho dentro da cultura predominante. Tal característica é evidente quando se pensa no romance realista ou modernista, embora já esteja presente em certas obras do século XVIII. Apesar de romancistas do período haverem mostrado inclinação aos gosto e anseios da burguesia emergente, seus retratos da sociedade geralmente ocultavam intenções polêmicas. Antes de serem espelho de interesses sociais coletivos, eles atuaram como instrumentos para a articulação de posicionamentos ideológicos inovadores, obedecendo às dinâmicas da nova esfera pública. ${ }^{5}$

${ }^{4}$ Com essa formulação não tenho intenção de explicar a "essência de romance" e esgotar todas as possibilidades do gênero, é claro. Valho-me da formulação para explicar apenas o momento inicial do romance inglês, de Defoe a Richardson. WATT (2010), VASCONCELOS (2007) e EAGLETON (2005) expressam formulações semelhantes a respeito da relação entre ficção romanesca e realidade social que caracterizou obras do período.

5 Isso é, o escritor do início da Modernidade posicionou-se menos um porta-voz da coletividade abstrata do que como um polemista que negocia conteúdos nos debates que, antes de tudo, interessam a seus leitores. Compare VASCONCELOS, 2007, p. 22-23; JOERES, 2003, p. 201. 


\section{0 romance no Século das Luzes: o caso de Pamela, or virtue rewarded}

Conta-se que, em 1739, dois comerciantes encomendaram um livreto com o então obscuro impressor Samuel Richardson. A ideia do livro era oferecer uma série de modelos de cartas pessoais e profissionais, com o fim de servir de guia para semi-literatos em seus negócios. O homem abraçou o projeto com avidez, pondo-se a fantasiar a troca de cartas entre personagens criadas por sua mente - naquele contexto, ele julgou ser essa a melhor metodologia para criar modelos verossímeis de correspondência. No meio de tais exercícios de imaginação, todo um quadro dramático ganhou forma - quadro em que uma jovem criada atormentada pelo patrão se punha a escrever longas cartas, dando assim vazão a sua angústia. A ideia cresceu de tal forma que, antes que o livreto encomendado aparecesse sob o lacônico título Familiar Letters on Important Occasions, o primeiro romance de Richardson já estava no prelo. ${ }^{6} \mathrm{~A}$ jovem criada ganhou o nome Pamela, e o romance, um subtítulo sugestivo: virtue rewarded.

Apesar de voltar a receber devida atenção da crítica a partir da segunda metade do século XX, a importância do livro para a tradição literária inglesa nunca deixou de ser evidente (VASCONCELOS, 2007, p. 26). Tornou-se um lugar-comum da anglística referir-se a Pamela, or virtue rewarded como pioneiro de seu gênero - embora haja uma tradição epistolar fora da Inglaterra que remonta ao século XVII (BECKER, 1964, p. 166). Richardson, porém, atualizou o gênero significativamente, acrescendo-lhe uma carga emotiva e atualidade inovadoras.

${ }^{6}$ O relato do contexto de gênese do romance é do próprio autor; ver sua carta a J. Stinstra datada a 02
de junho de 1753 em Vasconcelos (2007, p. 305). Ver também WARD; WALLER, 1985, p. 3; SEIGEL, 2005, p. 163-4.
Apesar de parecer um dispositivo simples, o uso da carta íntima como modo narrativo implica na alteração do contrato ficcional entre leitor e texto. Nele, não há possibilidade de interferência de uma voz que julga a ação dos caracteres; no lugar do narrador como autoridade, o narrador do romance epistolar ficcionaliza sua própria posição no texto, propondo-se como editor supostamente imparcial do material que compõe o livro. Por conseguinte, esse material é exposto de forma a poder falar por si mesmo. Cabe ao leitor interessado nos sentimentos e dilemas da personagem acompanhar seus desenlaces psicológicos, de forma que acompanhar uma narrativa dessa natureza não significa mais perseguir o fio de ação que culmina em um clímax, como no modelo episódico da épica tradicional. Aqui, o enfoque da narrativa migra da trama em si para a dimensão interior dos caracteres. Mais importante do que os eventos é a verdade psicológica que deles decorrem. ${ }^{7}$ O modelo do romance epistolar atingiu tamanho destaque na época que, de acordo com um levantamento de Mattenklott (1980, p. 187), cerca de setecentos romances epistolares a là Richardson foram lançados na Europa central entre 1740 e 1800.

Richardson era consciente de suas inovações. Sua correspondência é repleta de reflexões sobre o ofício do escritor, dentre as quais encontramos a convicção de que o romancista deve servir a dois senhores, provendo a seus leitores "[bom] exemplo" e "entretenimento". 8 Tal princípio não era de todo novo na época. Como Prado (1997, p. 16) e Vasconcelos (2007, p. 42-63) mostram, o principal desafio de um romancista de meados de 1740 já deixava de ser o desafio de prover entretenimento; abundavam na época livros medíocres de aventuras exclusivamente voltados a esse fim. 0 maior desafio era ser levado a sério; ao menos se o autor quisesse ser reconhecido pelo

7 Becker, 1964, p. 6. Sobre as especificidades do modo narrativo em questão, ver PETHES, 2007, p. 20 SAUDER, 2004, p. 248; HAUSER, 1999, p. 63; EAGLETON, 2009, p. 69-78.

8 Carta não datada a Lady Bradshaigh, citada em Vasconcelos, 2007, p. 303-4. 
establishment literário. Por isso o registro romanesco precisou passar por um árduo processo de assimilação em decorrência da falta de precedentes clássicos que o legitimassem, que lhe conferissem um posto seguro no rol dos gêneros sérios (MATTENKLOTT, 1980, p. 185). Considerando que o paradigma valorativo do século XVIII era o da estética neoclassicista, até a crítica literária romântica entrar em cena, toda forma de prosa de ficção foi ignorada pelos grandes sistematizadores da literatura. Prosa era sinônimo de registro literário banal, próximo demais da linguagem falada e, assim, maculado pela trivialidade do discurso cotidiano. Nesse sentido, o romance era tido como uma forma destituída de musa, alheia ao âmbito da grande arte.

Richardson tinha plena consciência da aversão dos intelectuais ao romance. Em sua correspondência encontramos diversas reclamações do gosto popular por trivialidades fantasiosas (que ele, como bom anglosaxão, chama de "maravilhoso francês"), algo que em momento algum o levou a desacreditar no potencial expressivo do gênero. "Eu detesto tanto o maravilhoso francês e toda a maquinaria desnatural", diz, "que estou disposto a abrir mão do meu lucro se puder instruir". ${ }^{9}$ A partir disso, encara-se o duro fato: se um romance já estava fadado a ser considerado esteticamente inferior, que ao menos fosse útil, e ensinasse a seus leitores não-aristocratas o que afinal não conseguiriam aprender em Plutarco (BECKER, 1964, p. 7, 11-12).

Tal necessidade levou o autor a um modo narrativo fiel à exploração da realidade. Richardson elegeu o realismo ${ }^{10}$ como a terceira e mais importante função da obra literária. Antes mesmo de entreter e ensinar, ela devia reproduzir a verdade, ou, no vocabulário do autor, "a natureza". Esse foi um elemento programático de sua escrita que considero o mais influente sobre 9 Carta a Stephen Duck, sem data; em Vasconcelos (2007, p. 302).
${ }^{10}$ Refiro-me a realismo, evidentemente, não como escola literária, mas no sentido que Watt (2010,
p. 9-36) deu ao termo. Comparar com a crítica de Eagleton (2005, p. 69-75) ao tipo de realismo proposto por Richardson. a tradição posterior. Richardson se diferenciava de seus predecessores por abrir mão do uso de personagens idealizadas em seu retrato dos costumes. Lemos em uma carta:

adotei em geral a natureza humana como ela é; pois não adianta supô-la angelical, ou tentar fazê-la assim; [...] se nós pudermos misturar adequadamente instrução e entretenimento, para fazer que o último pareça ser o objetivo, ao passo que o primeiro é o real propósito, imagino que grande coisa terá sido feita (Carta ao Dr. Cheyne, 31 de agosto de 1741, aparentemente nunca enviada, in VASCONCELOS, 2007, p. 300).

Personagens heroicas, ele as tratou por "monstros sem defeitos".11 Será nessa direção que a grande tradição do romance do século seguinte construiu seus argumentos contra o elitismo da arte das cortes. O novo paradigma artístico favorecia, no trocadilho de Mattenklott (1980, p. 185), "eine Kunst gegen das Künstliche" [uma arte contra o artificial, i.e. contra o artificialismo].

As três funções da literatura apontadas por Richardson se complementam: o livro só ensina conforme obtém sucesso em confrontar o leitor com situações verossímeis, que poderiam ser parte de sua própria experiência de vida. A partir daí, o autor pode sensibilizá-lo e confrontá-lo com um quadro de dilemas morais. 0 uso da razão e da sensibilidade leva o leitor a convencer-se, por meio de sua própria experiência reflexiva, de que a virtude é um caminho recompensador. É importante notar que a prescrição de princípios áridos de moral não daria conta de atingir esses objetivos. Como conselheiro espiritual de sua comunidade ${ }^{12}$, Richardson conhecia bem os limites da doutrinação sistemática. Ainda que a postura do autor seja própria de uma figura patriarcal, como afirma Hauser (1999, p. 60),

${ }^{11}$ Carta à senhora Mulso, 11 de julho de 1751, em Vasconcelos (2007, p. 303); ver também p. 624, nota 57. 12 Ver Ward; Waller (1985, p. 6-7) sobre o círculo de pessoas ilustres que se formou ao redor do autor após seu primeiro sucesso editorial. 
ela é também uma postura de respeito pela dignidade de seus pupilos. Esses pupilos são tratados como sujeitos autônomos, guiados por um senso de coerência interna.

A influência da fórmula do romance epistolar richardsoniano na literatura posterior é difícil de mensurar. A mistura de cartas e tratado de moral implicava em uma forma de entender o mundo social - um entendimento calcado tanto na exploração de autonomia do indivíduo quanto na análise crítica da realidade - e que, por sua vez, alterava significantemente a discussão sobre a virtude no registro literário. Tal análise foi e ainda é atrativa já que, nas palavras de Vasconcelos (2007, p. 51-52), "as contradições sociais e históricas estão não só presentes, mas configuram o teor de verdade das obras de arte, que reproduzem não o mundo, mas sua lógica".

A protagonista Pamela Andrews não põe à prova o valor das virtudes cristãs pressupostas na cultura predominante. Ela deve entender o que é virtude para uma mulher em sua situação, aceitando o fato de que, na vida prática, cada pessoa está pronta para defender sua própria ideia de retidão. A partir daí ela pode figurar de fato como heroína do romance. Seu maior antagonista é justamente o homem que, ao lhe fazer corte, a objetifica e fracassa em reconhecer seu valor individual, mr. B.

\section{A virtude como questão de política sexual}

O grande mérito de Pamela reside no dinamismo de suas páginas iniciais. Com enorme economia de linguagem, a protagonista dá a notícia da morte de sua patroa Lady B, partilhando as ansiedades decorrentes do evento. Sendo uma criada de origens humildes, Pamela corre o risco de ser dispensada dos serviços da família aristocrática para a qual trabalha desde criança (carta I; RICHARDSON, 2003, p. 43). Por ter sempre trabalhado com diligência, a patroa lhe devotou certa afeição e, em leito de morte, pediu que o filho zelasse pela menina. O pedido em si é vago demais para esclarecer o destino de Pamela, de modo que ela se encontra dividida entre o luto e a incerteza de seu futuro financeiro. Por fim, mr. B resolve mantê-la na equipe dos serventes, mostrando-se até mesmo amigável.

Pamela é um caso peculiar na história da literatura inglesa em função de sua condição social ambígua. Ao mesmo tempo em que é uma simples criada de quarto, sua educação é a do salão aristocrático. Nela estão encapsuladas as contradições próprias de quem se divide entre duas realidades sociais incompatíveis. No decorrer da trama, Pamela demonstra requinte em tratos sociais, um certo treino em artes (ibidem, p. 238), além de compartilhar a fragilidade que se não esperava ver em uma camponesa rústica daquele século. Acima de tudo, Pamela é bem articulada. Seus superiores repetidamente louvam sua capacidade de refletir e escrever sobre os próprios sentimentos, até que tal habilidade se reverte em um incoveniente para o poder estabelecido. Personagens como mr. B e mrs. Jewkes adquirem o hábito de desviar escritas pela criada, e invariavelmente não gostam daquilo que lêem. A palavra scribbler se torna o insulto mais comum que os dois se valem para chateá-la.

Por saber demais sobre o mundo que a circunda, sua escrita se torna cada vez mais perigosa. Na mentalidade dos patrões, não cabe a uma criada perder tempo com cartas (como expressa até mesmo sua amiga Mrs. Jervis na carta X; RICHARDSON, 2003, p. 54). No romance, a importância dada à escrita é bastante significativa; ela figura tanto como ato de expressão sentimental quanto como ato de resistência política. Não por acaso, Richardson opta por iniciar o conflito central da obra no instante em o nobre mr. B se depara com cartas que delatam seu uso abusivo de poder: "Well, no more of this silly girl [...] you may only advice her [...], if she stays here, that she will not write the affairs of my family purely for an exercise to her pen and her invention" (carta XIV; ibidem, p. 60). 
Em um outro trecho, mr. B volta a alertar:

she has written letters (for I find she is a mighty letter writer!) to her father and mother, and to others [...] in which, representing herself as an angel of light, she makes her kind master and benefactor, a devil incarnate. [...] let her be careful how she uses my name with freedom when she is gone from me" (carta XVI; ibidem, p. 68, meu grifo).

Ao escrever, a protagonista estaria decifrando, ou ao menos desestabilizando, a ordem social que mantém alguém como mr. B no poder. A necessidade do nobre manter sua honra publicamente leva-o a encarar o comportamento da criada como uma ofensa. Daí em diante, ele passa a persegui-la. Pamela gradualmente se volta contra as normas de decoro esperadas de si ao ponto de, em determinado trecho, declarar ter optado perder a reverência pelo patrão: "This wicked man - He cannot deserve to be called a gentleman. I believe I shall lose all my reverence for him" (ibidem, p. 246).

A consciência da arbitrariedade da divisão de estados lhe é clara desde o início do texto. A moça mostra certo prazer em julgar o comportamento de aristocratas da região pois assim pode constatar os vícios e a frivolidade característicos da classe. O objetivo de seus exercícios analíticos consiste em nada além de reafirmar sua superioridade moral em relação àquelas pessoas (ibidem, p. 81-87, 294-5). Na visão da serva orgulhosa, nada além da sorte de haver nascido em berço nobre justifica o fato de alguém como mr. B ser seu patrão e não seu subordinado. Poder reconhecer isso é apenas um dos motivos de seu orgulho no início do romance; o segundo motivo decorre da consciência das limitações próprias da gente simples. Pamela é consciente de tensões sociais que os pobres-diabos com quem trabalha, subjugados pelos caprichos de seus benfeitores, estão longe de identificar. A moça, em suma, é fadada a se isolar tanto de seus iguais quanto de seus superiores.
O único vínculo que permanece inquebrantável é aquele que mantém com os pais, John e Elizabeth Andrews. Pamela é uma filha dedicada e devota, mas mesmo assim fica a impressão de que há algo de problemático na comunicação entre sua geração e a de seus genitores. Usemos o exemplo da carta II, onde John Andrews tece comentários lacônicos sobre a morte de Lady B. Tais comentários, para ser mais exato, cabem em uma só frase (RICHARDSON, 2003, p. 45). Em contrapartida, nas duas páginas seguintes lemos uma série de prescrições e alertas à filha contra o comportamento licencioso de jovens nobres. A generosidade de um homem como o filho de Lady Davers deve ser questionada, já que é próprio de seu estamento aproximar-se de criadas com segundas intenções. Cito o trecho em questão:

[...] our chief trouble is, and indeed is a very great one, for ear you should be brought to anything dishonest or wicked, by being set so above yourself. [...] what avails all this, if you are to be ruined and undone! Indeed, my dear Pamela, we begin to be in great fear for you; for what signify all the riches in the world, with a bad conscience, and to be dishonest. [...] If, then, you love $u s$, if you wish for God's blessing, and your own future happiness, we charge you to stand upon your guard; [...] Arm yourself, my dear child, for the worst; and resolve to lose your life rather than your virtue (ibidem, p. 45-46 e 52).

Essa não é exatamente uma mostra de empatia paternal, embora reconheçamos em seguida que o temor do velho camponês se confirma: de fato o filho de Lady Davers carregava motivos ulteriores. Dentro de alguns dias, Pamela envia a primeira das muitas reclamações de assédio sexual investido pelo patrão (carta X; ibidem, p. 53 et seq).

No espaço de duas cartas, assim, o conflito de toda a obra está delineado. Richardson não foi um autor que seguiu um plano geral de escrita - ele próprio afirma ser um "escritor muito irregular"13 -, o que explica a extensão

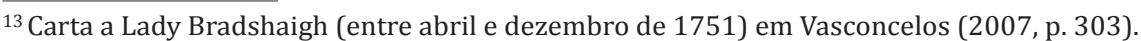


de suas obras. Por vezes, passam-se centenas de páginas sem que nada além de reflexões sejam registradas. Os momentos mais reflexivos do romance são justamente aqueles que o autor considerava propícios para a aprendizagem de seus leitores. ${ }^{14}$ Clarissa, o romance que procede Pamela, ocupou sete volumes na edição original, cerca de mil e quinhentas páginas nas edições atuais. $O$ preço que Richardson paga pelo uso do modo narrativo em questão é, assim, o risco constante de ser prolixo. ${ }^{15}$

De qualquer forma, nos momentos reflexivos do romance encontrase o desenvolvimento do tema que nos interessa aqui, o da virtude. Da segunda carta em diante, a protagonista internaliza a desconfiança do pai à boa vontade dos poderosos, dando início a uma longa reflexão sobre a relação entre classes e gêneros. Conforme nobres da região visitam a propriedade do patrão, Pamela passa a investir tempo em um exercício de análise comportamental da aristocracia frívola da Inglaterra setecentista. A propriedade da família B. logo se transforma em seu laboratório de análises sociais. É correto afirmar que a definição de sua própria identidade de mulher comum e virtuosa depende do reconhecimento das diferenças que a separa dos demais. A palavra virtude, da qual se vale repetidamente ao falar de si própria, representa muito mais do que outrora representou na tradição cristã: no quadro de luta de classes que se cria em sua mente, a virtude do pobre se contrapõe à honra do aristocrata. "A fine gentleman's notion of the word honour [...] and those of us common people, might be very different. He [mr. B] might also be a generous and kind landlord, and yet not a

${ }^{14}$ Sabemos por uma carta enviada ao Dr. Cheyne que, na realidade, a única parte realmente planejada de seus romances foi o início de Pamela. Como mencionei acima, em apenas um punhado de páginas o autor constrói toda a tensão da narrativa, com o intuito de "atrair a atenção do leitor". As quase 500 páginas restantes livro, por fim, são dedicadas à investigação dos sentimentos decorrentes dos conflitos, de onde o leitor supostamente pode derivar uma instrução. Ver Vasconcelos, 2007, p. 301.

${ }^{15}$ Vide carta a Lady Bradshaigh datada a 09 de outubro de 1756 em Vasconcelos (2007, p. 307) virtuous man", lemos em sua discussão com o fazendeiro Monkton (RICHARDSON, 2003, p. 142). Se por um lado a honra está ligada a meras aparências sociais, a virtude, por outro, prevê integridade de caráter e compromisso religioso. A inversão de valores operada na formulação é evidente. Ao questionar o código de comportamento da alta sociedade, Pamela contempla pela primeira vez a possibilidade de reforma social, de um acordo entre pobres e ricos (e, como veremos, entre ela e mr. B, seu futuro esposo). Ainda assim, é precipitado assumirmos que Pamela foi uma revolucionária no sentido moderno do termo; as atitudes que toma contra a nobreza são em geral inofensivas, e todo o conflito contra a aristocracia termina assim que ela própria se torna uma gentlewoman.

Antes que isso aconteça, Pamela denuncia indiscriminadamente tudo o que pertence à esfera da nobreza. Logo ela passa a renunciar qualquer contato com o mundo de opulência para legitimar-se simbolicamente dentro da categoria de mulher simples. Na carta XX (RICHARDSON, 2003, p. 76), lemos minúcias dos preparativos da volta de Pamela à casa dos pais. Em função de viver junto aos nobres desde os doze anos e, por isso, dispor de boas roupas, a criada decide encomendar roupas de camponesa com alguns vizinhos pobres e, assim, vestir-se como alguém de sua própria estirpe (ibidem, p. 57, 76-77). A ironia no episódio é que ela, para parecer simples, acaba tendo que dispor de mais dinheiro.

O comportamento de Pamela, portanto, não é de todo irreprimível. Por vezes, sua obstinação a torna censurável mesmo aos olhos dos demais criados. Custa-lhe entender que a crença de que a virtude é dádiva dos estamentos inferiores não passa de mais uma de suas ilusões. O dualismo moral criado em sua mente, no fundo, explica-se como uma forma de resistência ao estado paranóico que ela vive. Uma vez que mr. B deixa de ser uma ameaça à integridade física da moça, para tornar-se seu noivo, ela abandona seu exercício de crítica. Sabemos pelo título do romance que a virtude será 
recompensada e, como no mito tradicional de inocência perseguida, é de se esperar que o casamento constitua tal recompensa. Parte da tensão do romance reside nos inúmeros obstáculos enfrentados pelo casal até que se chegue no happy ending - ainda que cada vez mais a esperada reconciliação pareça improvável.

Richardson é esquemático na divisão dos obstáculos que constituem a trama do romance. Da carta I à XXX, lemos sobre dois avanços sexuais por parte de mr. B. Nesse meio tempo Pamela se considera enclausurada na casa do patrão de quem depende financeiramente, e a cada tentativa de sedução desmaia, escreve uma enxurrada de cartas para conhecidos, para então pedir que seja liberada para voltar à casa dos pais. Mr. B promete libertá-la, e após muitos rodeios coloca-a em uma carruagem. A carruagem a leva à casa do fazendeiro Monkton, subordinado da família B., onde lê a inesperada declaração de amor do patrão. De lá, a moça é levada a uma outra propriedade da família aristocrática, a mansão de Lincolnshire, vendo-se mais uma vez aprisionada e vigiada pela insensível mrs. Jewkes. Há um terceiro assédio sexual - "o pior de todos" (ibidem, p. 237-249) - após o qual mr. B renuncia seus hábitos deselegantes de cortejar moças. Posteriormente, o leitor tem consciência de que B. tenta conseguir chegar aos termos com John Andrews para, enfim, desposar a criada. Uma vez que o velho camponês consegue falar com a filha pessoalmente e pô-la à parte do casamento, a grande questão do romance se altera.

É possível que Denis Diderot tenha identificado esse exato momento da narrativa como momento crucial para entendermos o sentido da virtude em Richardson. Em seu Éloge de Richardson (1762), o filósofo questiona: “O que é a virtude? Ela é, sob qualquer face que a considerem, um sacrifício de si mesmo. [...] uma disposição preconcebida para imolar-se na realidade". Mais adiante, complementa:
Richardson semeia nos corações germes de virtude que aí remanescem de início ociosos e tranquilos: [...] sentimo-nos levados ao bem com uma impetuosidade que não sabíamos ter dentro de nós. Experimentamos, com o aspecto de injustiça, uma revolta que não poderíamos explicar a nós mesmos. (DIDEROT, 2000, p. 17-18) ${ }^{16}$

O aspecto mais importante nos apontamentos de Diderot é a mescla de sacrifício de si e revolta contra a injustiça do outro que constitui o conceito richardsoniano de virtude. É justamente essa a exigência imposta tanto a mr. B quanto a própria Pamela para que alcancem um acordo.

Aquilo que mr. B deve sacrificar em si parece ser bastante evidente sobretudo para o leitor guiado pela versão de Pamela de sua história de amor. Podemos deduzir a primeira condição imposta pela moça a partir de seu explícito horror por investidas sexuais antes da consumação do matrimônio - uma posição típica do puritanismo. Pamela, por fim, aceita ser cortejada, e só por isso permanece na casa do patrão, mesmo após os assédios (certamente brutos, desajeitados) que, em um primeiro momento, ela tacha de tentativas de estupro. Mas aos poucos ela aceita o jogo de sedução, contanto que seja tratada como mulher nobre e digna (ver seu diálogo com mrs. Jervis, RICHARDSON, 2003, p. 78 e 86)

Por fim, também Pamela deve sacrificar algo de si. A muito custo ela releva sua inimizade pela aristocracia, e aceita sua própria atração por $\mathrm{mr}$. B. Torna-se interessante pensar a possibilidade de um relacionamento conjugal que parta do acordo mútuo, pautado pela instituição da amizade e pelo reconhecimento da igualdade entre homem e mulher. Ian Watt (2010, p. 177) é bastante esclarecedor em sua análise dos diálogos presentes no

${ }^{16} \mathrm{~A}$ ideia de renúncia foi desenvolvida com mais detalhe somente na obra posterior de Richardson Em seu The History of Charles Grandison (1753), lemos uma formulação de virtude bastante próxima àquela sugerida por Diderot: "a vida de um homem de bem [é] uma guerra constante contra as paixões" (RICHARDSON apud WATT, 2010, p. 167) 
livro: "o diálogo entre os enamorados constitui não um exercício de retórica convencional, como nas novelas antigas, mas uma sondagem das forças que fizeram deles o que são". A desigualdade entre gêneros e classes na Inglaterra setecentista se presentifica como uma só força coerciva que os dois jovens devem compreender e enfrentar. As barreiras entre os amantes, portanto, não são externas e ocasionais (como foram nos casais de Shakespeare, se pensarmos em Romeu e Julieta, Antônio e Cleópatra); elas são internas, introjetadas, são qualidades adquiridas por cada um dos jovens em seu processo de educação.

Ainda assim, o modo que mr. B e Pamela atingem um consenso sobre questões sexuais advém do esforço quase exclusivo da moça. Richardson reproduz o mito chauvinista de que os homens são mais sujeitos à paixão sexual, de forma que caberia à mulher garantir o caráter sagrado da família e do casamento. ${ }^{17}$ Pamela o faz, mas sem ocultar sua repulsa pela ideia do sexo - como algumas pacientes histéricas de Freud, ela desmaia a cada avanço de mr. B - e justificando sua abstinência através de sua dedicação exclusiva a 'coisas superiores'18 - a escrita, o trabalho e a edificação espiritual. 0 sexo é relegado à camada mais profunda da intimidade do casal, como só um aspecto dentre muitos da vida a dois.

Em troca do controle de seus impulsos supostamente naturais, mr. B luta para que Pamela confie em suas decisões de 'homem do lar'. Ele passa por

${ }^{17} \mathrm{Um}$ trecho em especial deixa clara essa ideia do macho como animal instintivo: "I was driven by an irresistible impulse to it, and could not help it if I would" (RICHARDSON, 2003, p. 306, meu grifo) E curioso que esse argumento venha após mr. B mudar seu comportamento e se mostrar convencido de que se tornara um novo homem no instante em que superou sua impulsividade natural: "that I did intend what you call the worst, is most certain: and though I would not too much alarm you now, I could curse my weakness and my folly, which makes me own, that I cannot live without you. But, if I am master of myself, and my own resolution, I will not attempt to compel you to anything". (ibidem, p. 244)

${ }^{18}$ Watt, 2010, p. 170. O fato de Richardson retratar o comportamento de Pamela dessa forma tem curiosos patt, 2010, p. 170. O fato de Richardson retratar o comportamento de Pamela dessa forma tem curiosos paralelos com o desenvolvimento do código sexual da burguesia no século XVIII estudado por Michel não entra em questão desenvolver esse aspecto da visão de mundo richardsoniana. fase de ciúmes de um Mr. Williams - religioso local que tenta facilitar a fuga da criada - e depois de muito esforço a convence de que tem intenções de casamento legítimas. Sua maior dificuldade é ter de justificar suas atitudes para alguém que acostumou a ver como subordinada, como Mrs. Jervis afirma no seguinte discurso "My master [...] does not always inform his servants of his proceedings; but you need not doubt his honour: you have his hand for it" (RICHARDSON, 2003, p. 126-7).

Uma vez que mr. B aceita os termos da noiva, transformando-se em uma espécie de puritano (ibidem, p. 443), é a vez dela provar seu valor como futura nobre. A tarefa de comprovar que Pamela é uma companheira adequada para um nobre foi levada a sério por Richardson, que utilizou cerca de duzentas páginas do romance para justificar essa união pouco conservadora. Essa parte final da narrativa descreve apenas dois eventos: os preparativos de casamento e conflito do casal com Lady Davers, a irmã de B., que não aceita a ideia de o irmão macular o sangue da família (ibidem, p. 293 et seq, 401). Uma vez que Lady Davers se dá por satisfeita, o conflito está resolvido. Pamela, agora senhora B, pode colher os frutos de sua virtude recompensada e viver uma espécie de idílio puritano ao lado do marido, que conclui:

Tis true, my dear Pamela [...] we have sufficiently tortured each other: but we shall soon, I hope, be able to sit down together [...] and take pleasure in reflecting upon all our past difficulties. (ibidem, p. 303).

\section{0 romance do Iluminismo e o advento da crítica}

Em 1761, Henry Fielding lança uma paródia de Pamela de nome An Apology for the Life of Shamela Andrews. A heroína de Richardson aparece nela como uma hipócrita astuciosa cujo domínio dos recursos femininos lhe permite levar pelo nariz tanto o crédulo mr. B quanto seus leitores mais desavisados, ganhando simultaneamente o título de 
nobre e a simpatia do público inglês (WATT, 2010, p. 179-182; KEYBER [FIELDING], 1761, p. 6-8).

Sem dúvidas essa ambiguidade existe em Richardson; isso ocorre em função da própria forma narrativa monológica que ele emprega. Como tratado anteriormente, a narrativa é focada demais na intimidade das personagens para que haja espaço para uma visão objetiva dos fatos. A aposta de Richardson é que seu leitor aceite o ponto de vista de Pamela por força da empatia, relevando suas infantilidades e clara tendência de dramatizar a própria vida. $\mathrm{O}$ importante é que o leitor reconheça a causa defendida pela moça como justa, coerente e atual. Em Fielding, entretanto, Pamela oculta sua intenção premeditada de conquistar o patrão simulando inocência e virtude, de forma que não se torna mera amante dessa espécie de Don Juan, mas sua esposa, dona de seus bens.

Fielding está certo em propor o tema da defesa da castidade e virtude como parte integrante do ritual de galanteio entre mr. B e Pamela. Há uma impressão de extrema artificialidade no instante em que, no meio do livro, aquilo que começou como um violento conflito social se torna uma confusão comum da fase de interação inicial de um namoro. A meu ver, esses dois momentos são indissociáveis dentro da proposta do livro. A megera mrs. Jewkes mostra não compreender tal indissociabilidade quando confronta Pamela com a questão:

[...] how strangely you talk! Are not the two sexes made for each other? And is it not natural for a man to love a pretty woman? And suppose he can obtain his desires, is that so bad as cutting her throat? (RICHARDSON, 2003, p. 148).

A problemática não é meramente a da inocência perseguida, mas a do antigo mito do amor entre a moça simples e o jovem bon vivant, que, embora habitem universos virtualmente opostos, operam o autossacrifício para se tornarem iguais no matrimônio. O conflito social, portanto, é parte do em- bate entre duas concepções diferentes de sexo e casamento, dos papéis masculinos e femininos, que o casal precisou contornar para atingir um acordo.

A revolução dos costumes proposta por Richardson é, em um aspecto, conservadora. Tanto o nobre quanto a serva esclarecida devem sacrificar-se e aprender algo. Uma vez que o sacrífico se realiza, a ordem se restabelece. A virtude é recompensada em ambas as partes, ainda que o trabalho de Pamela pareça ter sido mais tortuoso. Richardson propõe a mulher como guia do homem para a virtude (e, analogamente, a burguesia educada como guia para a nobreza ociosa do século XVIII, conformada com seus privilégios). Os resultados desse esforço, ainda desconhecidos no presente da enunciação, só podem ser esperados como fruto da mésalliance: o futuro está nas mãos daqueles que nascerem após a resolução dos conflitos entre nobreza e terceiro estado. Isso torna o romance de Richardson um romance de esperança histórica, como formula Margaret A. Doody (in RICHARDSON, 2003, p. 16), e simultaneamente faz de si algo descontentador. É interessante como o motivo da mésalliance foi herdado de Richardson por diversos escritores setecentistas interessados em uma revolução conservadora da sociedade: o tema também está presente no Tom Jones de Fielding, e pareceu obcecar Goethe nas obras que escreveu durante a Revolução Francesa. Seja no Classicismo de Weimar, no Sentimentalismo richardsoniano ou no credo girondino, imperou a visão de que somente uma burguesia educada e esclarecida estaria apta a se unir ao universo da nobreza para, por fim, criar uma nova sociedade.

A tradição de romances sentimentais ao estilo de Richardson foi um fenômeno internacional de enorme importância para o estabelecimento de uma identidade própria do gênero e, posteriormente, do drama burguês, sobretudo entre 1740 e $1780 .{ }^{19} \mathrm{O}$ estudo dessa tradição nos provê um

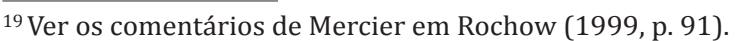


histórico de reações ao otimismo antropológico do autor. Aqui reside o que chamei no início deste trabalho de um 'debate' acerca do significado da virtude e da vida moral no mundo moderno. 0 que define o maquinário moral por trás do universo ficcional richardsioniano é o que lhe foi mais contestado: em um romance como Pamela, cada indivíduo virtuoso revive a história sacra da provação e da recompensa divina; a ordem universal é pressupostamente uma ordem em que a justiça impera.

O texto de Richardson, contudo, tem méritos inegáveis que nos fogem se quisermos julgar as intenções ocultas da protagonista Pamela, como fez Henry Fielding ao propô-la como uma mera social climber. Isso é um fato; Pamela efetivamente sobe de classe social. Se isso invalida seu bom caráter por oferecer algum perigo para uma ordem prevista para sociedades estratificadas, não importa mais ao leitor do século XXI; a questão fica relegada ao passado. $O$ interessante é pensarmos como a ambiguidade inerente ao romance dá abertura a uma ampliação da discussão da virtude em conjuntura com aspectos sociais influentes na vida dos indivíduos. Somente essa forma de exposição permitiu uma proposta de revisão da política sexual e social indissociável da defesa da vida virtuosa. A causa de Pamela, enfim, pode interessar um leitor do século XXI na medida em que, primeiramente, oferece uma visão retrospectiva das conquistas sociais da burguesia sobre as classes dirigentes do regime antigo e, em segundo lugar, de como uma crítica dos poderes estabelecidos foi articulada e legitimada em uma sociedade onde críticas eram, via de regra, silenciadas. O código da virtude formulado no romance é atrativo por sua atuação à sombra de outros códigos bem estabelecidos; ele expõe uma jovem que remete a um conceito até então restrito à esfera religiosa (pensemos nas virtudes cardinais católicas, na Psychomachia de Prudentius) e termina recompensada por guiar-se pelo senso de justiça interna que ela ousa seguir (sapere aude!).
De forma geral, Richardson se aliou ao projeto crítico formulado por grande parte da filosofia do Iluminismo. Até a Revolução Francesa, essa crítica da sociedade de estados não foi feita explicitamente contra a monarquia, mas contra as injustiças decorrentes dela. Artistas e filósofos teceram suas objeções em nome de um sistema jurídico puro, ditado pela razão e senso interno de justiça supostamente disponível a todo indivíduo que quisesse se esclarecer, e o alvo central das objeções foi uma classe dominante que se colocava acima das leis (FOUCAULT, 2013, p. 98-99). Esse dado excluiria os romances richardsonianos da categoria de obras moralistas no sentido tradicional do termo, noção ainda vigente em certa historiografia literária que expus no início desse trabalho. A religiosidade sem dúvida é um elemento forte no pensamento richardsoniano, mas devemos nos questionar qual é o seu verdadeiro papel em Pamela. Como observa Koselleck (1999, p. 15), em certas manifestações de religiosidade ilustrada, o próprio plano divino de salvação se transforma, tornando-se um planejamento do futuro feito por uma nova elite moralmente justa e guiada pela razão - pensemos aqui na mésalliance de mr. B e Pamela como momento simbólico em que essa nova classe mista nasce. Segundo Koselleck, "para fazer valer seus direitos, a crítica do século XVIII teve que se tornar utópica", valendo-se do moralismo sempre com vistas a um futuro mais justo e humanitário. A ideia de autossacrifício apontada por Diderot explica a fórmula do moralismo em questão; tratavase de um moralismo renovado, com outros fins distintos dos da moral da tradição cristã, já que visava reformas das relações sociais.

No entanto, reduzir Richardson a mero popularizador da filosofia do Iluminismo não permite que vejamos o que há de particular na rica tradição literária do século XVIII. As formas da crítica foram inúmeras, e devem ser estudadas em sua particularidade. De forma geral, os grandes romancistas do período discordavam uns dos outros em suas soluções para a sociedade, embora partissem do mesmo ponto: era preciso repensar as formas de 
interpretar e representar o mundo. Seus embates geraram uma grande variedade de retratos da sociedade e do futuro que se lhe almejava, e tais retratos encontraram continuidade na tradição romanesca posterior.

Retraçar a história dessa continuidade nos permite voltar a um interessante momento em que o romance era desprezado como gênero inexpressivo e fútil. Como mencionei há algumas páginas, de acordo com os paradigmas neoclássicos que julgaram a literatura por séculos, faltava ao romance uma musa. Na altura de 1765 , porém, Voltaire - mais consciente que qualquer um dos usos da literatura para a crítica das tradições - lhe confere a musa que faltava: "A crítica é a décima musa que finalmente apareceu [...] e varrerá a tolice do mundo" (VOLTAIRE apud KOSELLECK, 1999, p. 102).

\section{Referências}

ALT, Peter-André. Aufklärung. Stuttgart/Weimar: J.B. Metzler, 2007.

BECKER, Eva. Der Deutsche Roman um 1780. Stuttgart, J.B. Metzler, 1964.

CASSIRER, Ernst. Die Philosophie der Aufklärung. Hamburg: Felix Meiner, 2007.

DIDEROT, Denis. Obras II: Estética Poética e contos. Trad. J. Guinsburg. São Paulo: Perspectiva, 2000.

EAGLETON, Terry. The English Novel: An Introduction. Oxford: Blackwell, 2005.

FOUCAULT, Michel. História da Sexualidade 1: A Vontade de Saber. Trad. M. T. Albuquerque e J. A. Guilhon Albuquerque. Rio de Janeiro: Graal, 2013.

FULDA, Daniel. Wie identifiziert man ein Kulturmuster der Aufklärung? Rückblick auf den Grazer Workshop und Ausblick. Graz, 2011. Disponível em: <http://www.izea.uni-halle. de/cms/fileadmin/documents/projekte/kulturmuster_der_aufklaerung/workshop_ graz_2011/fulda_rueckblick.pdf>. Acesso em: 01 mar. 2014.

KEYBER, Conny [Henry Fielding]. An Apology for the Life of Shamela Andrews. London: Dodd, 1761.

HAUSER, Arnold. The Social History of Art. New York, Routledge, 1999. Vol. III. JOERES, Ruth-Ellen (Ed.). História da Literatura Alemã. Lisboa: Verbo, 2003.
KOSELLECK, Reinhart. Crítica e Crise. Rio de Janeiro: Contraponto (PUC-Rio), 1999. PETHES, Nicolas. Zöglinge der Natur: Der literarische Menschenversuch des 18. Jahrhunderts. Göttingen: Wallstein Verlag, 2007.

PRADO, Raquel de Almeida. Perversão da Retórica, Retórica da Perversão: Moralidade e Forma Literária em As Ligações Perigosas de Choderlos de Laclos. São Paulo: Ed. 34, 1997. RICHARDSON, Samuel. Pamela, or virtue rewarded. London: Penguim Books, 2003. ROCHOW, Christian. Das bürgerliche Trauerspiel. Stuttgart: Reclam, 1999.

SAUDER, Gerhard. Empfindsamkeit. In: DAHNKE, Hans-Dietrich; Otto, Regine. Goethe Handbuch, Band 4/1. Stuttgart \& Weimar: J.B. Metzler, 2004, p. 248-252.

SIEGEL, Jerrold. Adam Smith and Modern Self-fashioning. In: Siegel, Jerrold. The Idea of the Self: Thought and Experience in Western Europe since the Seventeenth Century. Cambridge: Cambridge University Press, 2005. p. 139-168.

STANITZEK, Georg. Um 1800. In: VOGL, Joseph (Ed.). Poetologien des Wissens um 1800. München: Fink, 1999. p. 249-265.

VASCONCELOS, Sandra Guardini. A Formação do Romance Inglês. São Paulo: Aderaldo \& Rothschild: Fapesp, 2007. (Linguagem e Cultura, 39).

WARD, Adolphus William; WALLER, Alfred Rayney. The Cambridge History of English Literature. Cambridge: Cambridge University Press, 1985. Vol. X.

WATT, Ian. A Ascensão do Romance: Estudos sobre Defoe, Richarson e Fielding. Trad. Hildegard Feist. São Paulo: Companhia das Letras, 2010.

Recebido em 20 de dezembro de 2014.

Aceito em 15 de maio de 2015. 